\title{
ENSAIO \\ ATIVIDADES DE APRENDIZAGEM NA ESCOLA
}

\author{
ESSAY \\ LEARNING ACTIVITIES AT SCHOOL \\ ENSAYO \\ ACTIVIDADES DE APRENDIZAJE EN LA ESCUELA
}

Renan Antônio da Silva 1

Pedro Demo ${ }^{2}$

Felipe Freitas de Araújo Alves ${ }^{3}$

\section{INTRODUÇÃO}

A escola sofre de inúmeros problemas que os próprios modismos das políticas educacionais não se cansam de desfilar, conforme a vez. Atualmente, a questão maior seria "ideológica", como resultado de política educacional à la Paulo Freire, mais preocupada com querelas esquerdistas doutrinadoras do que com os valores pátrios. Em alguns lugares, tentase uma espécie de "militarização" da escola, com a presença definitiva da PM, até mesmo na direção gerencial, porque se admite que "disciplina" estaria no centro da formação humana. No DF temos 4 escolas militarizadas, com o aval explícito da comunidade escolar, mesmo sem consenso pleno. Há algum tempo, a escola estava predestinada a ser um reduto de combate ao neoliberalismo, em nome da emancipação dos estudantes, mesmo que a aprendizagem estivesse em bancarrota. $\mathrm{Na}$ prática, a escola ainda é aquela descrita sarcasticamente por Chaplin em "Tempos Modernos" (2019): padronizada, repetitiva, uniformizada, chatíssima, improdutiva. O que mais chama a atenção é que, com dados profusos disponíveis, que o próprio MEC/Inep fabrica, não se consegue descobrir que o problema mais grave - entre tantos problemas graves - é falta de aprendizagem (Demo, 2017; 2018). Os modismos que se sucedem apontam para problemas reais também, como

\footnotetext{
${ }^{1}$ Pós Graduação em Direitos Humanos e Cidadania da Universidade de Brasília - UnB. Pesquisador Titular no Departamento de Pesquisa do Centro Universitário do Sul de Minas (Unis). Professor Visitante no Programa de Pós - Graduação em Educação da Universidade Federal do Amazonas - UFAM. E-mail: r.silva@unesp.br

${ }^{2}$ Pós-doutorado na UCLA/Los Angeles (1999-2000). Doutorado em Sociologia - Universität Des Saarlandes/Alemanha (1971). Professor titular aposentado da Universidade de Brasília, Departamento de Sociologia. Professor Emérito. E-mail: lepp@ rc.unesp.br

${ }^{3}$ Doutorando em Educação pela Universidade Federal do Amazonas. E-mail: felipe.jhs@ @otmail.com.
} 
doutrinação por vezes explícita, apego à "moral e cívica" de moralistas que sempre pregam a moral não têm, indisciplina por vezes terminal etc. Mas não são os mais contundentes, aqueles que "matam" a escola. Precisamos, certamente, lidar com a indisciplina na escola, sobretudo em locais onde a violência se tornou cotidiana e fatal. As escolas que decidem trazer a PM para dentro da escola num processo de decisão comunitária limpa precisam ser respeitadas. A expectativa de que assim vamos melhorar o Ideb, pode até ser real, mas não é uma proposta de aprendizagem; é de "treinamento". Ideb facilmente sobe com mera decoreba, por exemplo, quando se "treina" toda semana o Ideb! A finalidade precípua da escola não é o Ideb, mas formação intelectual e ética do estudante, o que implica disciplina, mas não faz dela sua razão maior de ser. É instrumentação.

Numa escola onde não existem "atividades de aprendizagem", apenas "aula, prova e repasse", podemos ter a disciplina mais férrea do mundo, e não vamos além do treinamento domesticador. Colocar os alunos para marchar é fútil, também porque não tem importância para a formação deles. Mas cuidar que a escola tenha ambiente de civilidade bem curtida, de interações respeitosas e colaborativas, de relacionamentos edificantes entre professores e alunos, de participação familiar e comunitária elevada, só faz bem. Também de modismos podemos aprender alguma coisa, mas são ventos que passam ao lado, por vezes distantes, desviando a atenção para o que mais dói na escola: ficar nela 12 anos e sair quase analfabeto, como é o caso em matemática: em 2017, apenas $4.52 \%$ dos estudantes do ensino médio aprenderam (Saeb, 2018). Para aprender, em especial aprender como autor (Demo, 2015), é importante que a escola tenha disciplina, não doutrine os estudantes, cultive a civilidade, mas principalmente precisa garantir o direito de aprender, que hoje está em pandarecos.

\section{ATIVIDADES DE APRENDIZAGEM}

São aquelas que incentivam a autoria discente, sob orientação/avaliação docente, destacando-se: ler, estudar, pesquisar, elaborar, argumentar, fundamentar. Não se ignora conteúdo, mas a chave não é engolir conteúdo; é ser autor dele, reconstruindo sistematicamente, como se preconiza hoje na neurociência e biologia da aprendizagem (Hoffman, 2019), para além do que classicamente as ciências sociais, desde a maiêutica socrática, indicavam: aprender vem de dentro, é autoria individual e coletiva, através da qual 
formamos a capacidade de dar conta da existência. Hoffman prefere o termo "reconstrução" (não "construção"), por ser mais realista: aprender não é inventar do nada - pretensão inviável - mas refazer o que já existe, como procede a biologia: seres são feitos de outros seres, numa forja infinda, sempre renovada. Aprendizagem implica autorrenovação constante do aprendiz que assim precisa manter-se a vida toda. Não é apenas exigência do mercado, que sempre precisamos levar em conta, pois trabalhar é preciso, mas sobretudo exigência da vida em sociedade. Trata-se de formação, não de treinamento. Quando bem feita, aprendizagem pode ser emancipatória. Quando mal feita, como é o caso em muitas escolas públicas, enterram-se os sonhos de multidões que só teriam na vida esta chance. Papel do professor, classicamente bem modulado na zona do desenvolvimento proximal de Vygotsky (1989; 1989a), é "puxar" para cima os desafios de aprendizagem (em inglês usa-se o termo "scaffolding", na metáfora do andaime), orientando e avaliado dedicadamente, também personalizadamente.

$\mathrm{Na}$ escola, porém, temos essencialmente "aula, prova e repasse", por conta do instrucionismo avassalador que acomete os professores, quer sejam das esquerdas, ou da direita. O professor que declama Paulo Freire todo dia, para desgosto da direita, também só dá aula, pois crê que sua função é transmitir conteúdo, religiosamente. Mas o outro professor preocupado com moral e cívica, disciplina, também só dá aula. As políticas educacionais - se olharmos desde o governo FHC até hoje (só porque o Ideb começa lá) - nunca descobriram que o mal mais entranhado na escola é falta de aprendizagem, à revelia dos dados que assim berram. Em geral, apostamos em aula, mais aula; por isso aumentamos o ensino fundamental de oito para nove anos de modo completamente contraproducente: os anos finais só pioraram. $\mathrm{Na}$ universidade, naturalmente, só temos aula, prova e repasse, com exceções (por exemplo, onde há algum Pibic), nomeadamente na pós-graduação stricto sensu (mestrado e doutorado), onde vale a autoria do candidato: cuida-se dela, não de aula. A universidade sabe o que é aprender como autor, pois pratica isso sistematicamente em sua elite acadêmica, mas não vale para a graduação (Demo, 2017a). Pedagogia e licenciaturas persistem como os cursos mais fracos, que estudo recente do BID (2018) chama de "refúgio", por ser via facilitada para se ter um diploma insignificante. Quando se aplica o questionário ao estudante de 15 anos de idade no PISA, pergunta-se também se gostaria de ser professor. Latino-americanos são afirmativos em 5\%, o que já indica uma profissão temerária, mas, quando se analisam as matrículas universitárias, aparecem $20 \%$ de matriculados em algum curso de educação. Embora seja equívoco "culpar" o professor, porque é uma peça num mundo complexo escolar e social, nem há correlação mecanicista entre docência e discência, ele é problema certamente, mas é 
mormente a melhor solução. Professor que sabe aprender é tábua de salvação dos alunos, porque tem grande chance de cuidar que eles aprendam, não apenas tenham aula.

É por isso que a mudança escolar é mudança docente, substancialmente. Professor não pode ser vítima de mudança; é seu protagonista fundamental. Sua função mais básica é construir na escola ambiente adequado para aprendizagem autoral dos estudantes, tendo o currículo sempre presente como instrumentação oficializada. Entre as primeiras providências está superar os "50 minutos de aula", porque são uma impropriedade gritante em termos de aprendizagem. Neste tempo minúsculo e estereotipado não se pode fazer bem nenhuma atividade de aprendizagem, no máximo empurrar conteúdos que muitas vezes sequer são entendidos, em especial em matemática. Para calçar a noção de aprendizagem autoral podemos usar a ideia do "educar pela pesquisa", que hoje é um patrimônio generalizado em experiências mais avançadas de aprendizagem emancipatória. Pesquisa é referência para a autoria do estudante, dentro de seu contexto, idade, fluxo escolar, porque promove atividades de aprendizagem (Cooper \& Murphy, 2016. Larmer et alii, 2015. World Band, 2018). Não pretende ser a salvação da lavoura, nem metodologia única, muito menos salvacionista, mas tão somente uma plataforma que promove o cuidado com a aprendizagem bem feita do estudante. Podemos também assumir a noção já bastante comum de que precisamos fazer do estudante um "autor, cientista, pesquisador", não porque esta alusão se faz no mercado hipocritamente (Dintersmith, 2018. Means, 2018. Pahomov, 2014. Bok, 2017. Posecznick, 2017), mas porque precisamos desse nível de autonomia para dar conta da sociedade do século XXI (Eyler, 2018. Davidson, 2017. Boykin \& Noguera, 2011. Knudsen et alii, 2017. OECD. 2015). Não é o caso voltar a fórmulas prontas, como é, acima de tudo, a aula canônica copiada para ser copiada (Bruyckere et alii, 2015), mas arranjar uma escola que realmente se dedique a atividades de aprendizagem do estudante, o que sempre supõe professores que gostam de aprender, e são, de direito e de fato, não profissionais do ensino, mas da aprendizagem. Esta habilidade foi denegada na faculdade, que insistiu apenas no profissional do ensino (dar aula, repassar conteúdo curricular), tornando-se crucial reconstruí-la na escola, por iniciativa dos próprios professores.

$\mathrm{Na}$ noção do "autor, cientista, pesquisador", que, para muitos é compromisso que começa no pré-escolar (Linn \& Eylon, 2011. Slotta \& Linn, 2009), encaixa-se "educação científica", não no contexto positivista corrente tipicamente colonialista e insustentável, mas "crítica autocrítica", tipicamente formativa, capaz de apreciar e questionar ciência. É fundamental que o estudante aprenda a pesquisar, a construir textos cada vez mais científicos, 
se familiarize com métodos e técnicas, bem como com metodologia científica, incluindo-se igualmente programação digital (forma básica de "alfabetização") (Rushkoff, 2010. Manovich, 2013) para que tenha devida autonomia criativa na sociedade/economia do conhecimento, profundamente digitizada. É simplesmente questão de coerência esperar que os professores tenham tais habilidades à flor da pele, que precisam reconstruir na escola em iniciativas próprias e/ou apoiadas por políticas educacionais. Como o aluno não elabora nada (basta ver o Enem-2018: cerca de 50 tiram nota máxima em redação; 112 mil, zero; em quase 4 milhões) (Kapa, 2019), a primeira será algo como 5 mal traçadas linhas. Não importa. Importa que essas 5 linhas virem 5 páginas no fim do ano, cientificamente adequadas.

O aluno comparece, não para escutar aula, embora isso possa ocorrer eventualmente, mas para curtir sua autoria, individual e sobretudo coletiva, sob o olhar atento orientador e avaliador do corpo docente. A escola deve assumir o ambiente de "comunidade de aprendizagem", onde todos, sem exceção, contribuem para que o estudante aprenda como autor (Pacheco, 2014; 2017), de laboratório generalizado onde os estudantes pesquisam, discutem, argumentam e também exponham seus feitos intelectuais. A sala de aula vai virando referência ultrapassada, porque sempre repõe o instrucionismo como sina escolar, prendendo os estudantes em atividades de mera instrução. Avalia-se, não mais por prova, mas por aquilo que o estudante produz, um modo muito mais pertinente (avaliação perfeita não existe, nem é possível) de diagnosticar e prevenir, garantindo o direito de aprender bem, um por um. Na produção própria do estudante - que ele guarda sucessivamente em seu portfólio individual podemos diagnosticar seus avanços e dificuldades, sendo viável personalizar a orientação e a avaliação, cuja finalidade única é cuidar do estudante. Trabalho mal feito é refeito, até ficar bom. Não se dá nota pela média do período, mas pela conquista final. A meta é que todos aprendam da melhor maneira possível, em seu ritmo próprio, envidando-se todos os esforços para que ninguém fique para trás; com bom diagnóstico diário/constante, é possível intervir para evitar o percalço. Ao mesmo tempo, na produção do estudante é logo visível o que está mal posto, sobretudo em matemática, sendo, então, o caso cuidar para que o estudante consiga se recuperar, por qualquer iniciativa que seja produtiva. A melhora do Ideb será resultado natural da aprendizagem, não de "treinamentos" fraudulentos (Lang, 2013).

\section{PLANEJAMENTO COLETIVO E INTERDISCIPLINARIDADE}


Mudança fundamental docente, além de desconstruir os "50 minutos", é fazer planejamento coletivo interdisciplinar, via projetos longos e avantajados de pesquisa. Para esclarecer este desafio docente fundante, ofereço aqui um exercício estereotipado, a título de exemplificação, tão-somente. Vou manejar um tema comum - água - apenas como referência indicativa, congregando todos os docentes sob este guarda-chuva. Para logo desconstruir os "50 minutos", sugiro um processo de pesquisa de 4 semanas seguidas, que os professores precisam organizar coletivamente, passo a passo, resguardando o currículo, mas principalmente gerindo o processo de autoria estudantil. Podemos subdividir o período como se achar por bem, ou, no mais óbvio, semana a semana. Assim, cumpre organizar a primeira semana, propondo leitura, estudo, pesquisa, elaboração etc., de modo individual e sobretudo coletivo, com produção constante, até mesmo diária, também para que se possa diagnosticar sempre de perto e personalizar este cuidado.

A primeira semana terá um tom preparatório, introdutório, também de "aquecimento", ademais de promover "atividades de aprendizagem" como referência central.

\begin{tabular}{|c|c|c|}
\hline \multicolumn{3}{|c|}{ SEMANA 1} \\
\hline Dia & Tópicos & Objetivo \\
\hline 1 & $\begin{array}{l}\text { Convém começar com algum gesto de motivação coletiva dos estudantes, } \\
\text { desde que não seja "apelativo". Este cuidado pode ser repetido no começo } \\
\text { de cada semana. } \\
\text { Podemos propor, para iniciar, leitura geral sobre o tema, sua importância } \\
\text { no mundo, questões de sustentabilidade, escassez crescente de água etc. } \\
\text { Pode ser individual ou em grupo, devendo-se ter claro o que é "ler" ("ler a } \\
\text { realidade") (Freire, 1989); fica bem ler escrevendo, para verificar se houve } \\
\text { entendimento adequado. } \\
\text { O dia pode ser dedicado a esta preparação, de manhã e de tarde, com } \\
\text { atividades intermediárias/intermitentes, para não cansar ou ficar } \\
\text { monótono; mas pode-se agregar alguma atividade de pesquisa, como } \\
\text { buscar textos sobre água na internet, no celular, na web em geral, ou } \\
\text { alguma discussão sobre "água" em Campo Grande, se o acesso é geral e } \\
\text { adequado, se o tratamento da água está em dia etc., desde que se defina } \\
\text { adequadamente o que é "discutir": não é chutar, tagarelar, ou vociferar, } \\
\text { mas "argumentar" - fundamentar da melhor maneira possível o que se } \\
\text { diz, fazendo-se ao final, uma elaboração coletiva (em grupos, de até cinco). } \\
\text { Pode-se concluir o dia com uma apresentação coletiva dos resultados, para } \\
\text { valorizar os esforços. }\end{array}$ & $\begin{array}{l}\text { Introduzir o projeto } \\
\text { de pesquisa de } 4 \\
\text { semanas; assegurar a } \\
\text { carga curricular } \\
\text { prevista; estabelecer } \\
\text { o cuidado com a } \\
\text { autoria, razão de ser } \\
\text { da pesquisa; manter } \\
\text { água como tema } \\
\text { gerador } \\
\text { interdisciplinar. }\end{array}$ \\
\hline 2 & $\begin{array}{l}\text { Representar a totalidade do currículo no tópico "água" (desde artes à } \\
\text { matemática, passando por cada conteúdo curricular), para se ter uma ideia } \\
\text { da interdisciplinaridade em termos práticos. } \\
\text { Pode-se passar o dia armando esta representação: como encaixar } \\
\text { matemática, artes, língua portuguesa, física/química, história etc., com } \\
\text { produção constante discente. Oferecer aos estudantes uma pletora de } \\
\text { textos, imagens, vídeos, áudios, palestras que tratem do tema de modo } \\
\text { interdisciplinar. } \\
\text { Vale pesquisar a situação da água no planeta, seus desafios maiores ou } \\
\text { dramáticos. Sua falta, aquecimento global, futuro da crise da água etc., com } \\
\text { devida produção própria individual e/ou coletiva. }\end{array}$ & $\begin{array}{l}\text { Água vista de todos } \\
\text { os ângulos possíveis, } \\
\text { em textos de todas as } \\
\text { modalidades } \\
\text { (impressos, vídeos, } \\
\text { imagens/fotos, } \\
\text { áudios, teatro, filme } \\
\text { etc.). Papel da } \\
\text { problematização } \\
\text { para motivar os } \\
\text { estudantes. }\end{array}$ \\
\hline
\end{tabular}




\begin{tabular}{|c|c|c|}
\hline & $\begin{array}{l}\text { Para armar uma discussão mais útil, é sempre o caso, primeiro, preparar- } \\
\text { se (ler, estudar, escrever), para só depois oferecer contribuição ao grupo, } \\
\text { para daí seguir um texto coletivo substancioso (em grupos). Convém evitar } \\
\text { o "brainstorming" por ser tiroteio perdido e induzir a chutar sem base. }\end{array}$ & \\
\hline 3 & $\begin{array}{l}\text { Dia da Metodologia } \\
\text { De manhã: o que é pesquisar: } \\
\text { - princípios de métodos e técnicas } \\
\text { - metodologia científica; pesquisa quantitativa e qualitativa } \\
\text { - dados, como fazê-los, como interpretá-los } \\
\text { - pesquisa como condição da autoria. } \\
\text { Terminar a manhã com alguma produção escrita coletiva } \\
\text { De tarde: o que é texto científico: } \\
\text { - texto é um "tecido", com começo/meio/fim } \\
\text { - discurso com base na autoridade do argumento, não do argumento de } \\
\text { autoridade } \\
\text { - fundamentar o que se diz, sem pretender fundamento último } \\
\text { - exemplo da Wikipédia - ciência aberta - crítica autocrítica } \\
\text { Terminar a tarde com algum produção coletiva, também multimodal. }\end{array}$ & $\begin{array}{l}\text { Cultivar habilidades } \\
\text { de aprendizagem, em } \\
\text { especial a de } \\
\text { pesquisar e de } \\
\text { elaborar } \\
\text { cientificamente. }\end{array}$ \\
\hline 4 & $\begin{array}{l}\text { Pesquisa por grandes áreas } \\
\text { 1. De manhã: Nas ciências exatas e naturais, sobre o tema da água } \\
\text { (suporte docente com textos, vídeos, imagens etc.) } \\
\text { Matemática da água } \\
\text { Física/química da água } \\
\text { Biologia da água etc. } \\
\text { 2. De tarde: Nas ciências humanas e sociais } \\
\text { Água e literatura (Língua Portuguesa) } \\
\text { História/geografia da água } \\
\text { Sociologia, filosofia da água } \\
\text { Artes (poesia, pintura, literatura, teatro, TV, filmes) } \\
\text { Educação física (trilhas, caminhadas, cuidado com o corpo, beber água). }\end{array}$ & 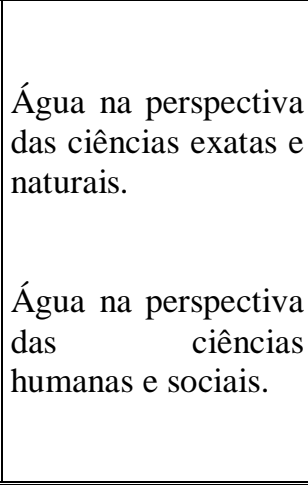 \\
\hline 5 & $\begin{array}{l}\text { Último dia da primeira semana: olhar interdisciplinar da água } \\
\text { 1. De manhã: com base no material estudado nos dias anteriores, fazer um } \\
\text { texto coletivo sobre "Água como bem comum", interdisciplinar, } \\
\text { Pode-se terminar a manhã com exposição dos textos ou de um ou outro. } \\
\text { 2. De tarde: Desafios interdisciplinares planetários da água como bem } \\
\text { comum } \\
\text { Texto individual (multimodal, de preferência) } \\
\text { Pode-se terminar a tarde com exposição sorteada de textos individuais. }\end{array}$ & $\begin{array}{l}\text { Colheita semanal: o } \\
\text { que se aprendeu na } \\
\text { trajetória de pesquisa } \\
\text { e elaboração, } \\
\text { individual e/ou } \\
\text { coletiva. }\end{array}$ \\
\hline
\end{tabular}

\section{Papel Docente}

Avaliando todo dia a produção discente, diagnosticar a situação geral, mas sobretudo a de cada estudante, indicando déficits mais notáveis (matemática, por exemplo). Usar isso como orientação personalizada. Acompanhar o desenrolar da semana para atestar acertos e equívocos no planejamento. A organização acima pode ser considerada rígida demais ou de menos. Avaliar a propriedade dos textos multimodais. Sempre observar a motivação intrínseca dos estudantes. Feedback constante e rápido.

A segunda e a terceira semana podem ser vistas como prática sistemática de pesquisa

e elaboração científica, elevando-se as exigências gradativamente, conforme a "zona do 
desenvolvimento proximal", respeitando-se ritmos e expectativas sempre que possível. A

ideia é aprender pesquisando, aprimorando a autoria científica, crítica autocrítica.

\begin{tabular}{|c|c|c|}
\hline \multicolumn{3}{|c|}{ SEMANA 2} \\
\hline Dia & Tópicos & Objetivo \\
\hline 1 & $\begin{array}{l}\text { Água no MS e em Campo Grande } \\
\text { Dia inteiro de pesquisa sobre este tópico, com apoio docente em termos } \\
\text { de textos, vídeos, fotos, que signifiquem "problematizações" } \\
\text { instigantes para os estudantes. Cuidar que o currículo seja considerado, } \\
\text { em todas as áreas pertinentes. Bom uso da internet, web, Wikipédia etc. } \\
\text { Questão dos rios no estado. Pantanal. Manejo dos rios e córregos em } \\
\text { Campo Grande. Encaixe disso tudo na carga curricular. } \\
\text { Pesquisa coletiva como regra, em grupos. Pode haver divisão de } \\
\text { trabalho por áreas, se for o caso, sem perder a interdisciplinaridade. } \\
\text { Terminar o dia com pelo menos um artigo científico reconstruído em } \\
\text { grupo, que não seja mera resenha ou relatório, mas tipicamente } \\
\text { "analítico". }\end{array}$ & $\begin{array}{l}\text { Trazer a pesquisa } \\
\text { sobre água para perto } \\
\text { da vida dos } \\
\text { estudantes. }\end{array}$ \\
\hline 2 & $\begin{array}{l}\text { Continua pesquisa, agora voltada para uma elaboração individual no } \\
\text { fim do dia, capaz de congregar a carga curricular abrangente } \\
\text { (matemática, física/química, história/geografia, poluição das águas } \\
\text { etc.) } \\
\text { Fim do dia: duas horas para elaboração individual de um texto com } \\
\text { pretensões científicas. }\end{array}$ & $\begin{array}{l}\text { Água como desafio } \\
\text { bem perto } \\
\text { cotidiano. }\end{array}$ \\
\hline 3 & $\begin{array}{l}\text { Água que bebemos -1 } \\
\text { De manhã, visita à estação de tratamento da água em Campo Grande } \\
\text { (organizar isso com sabedoria e segurança, conforme a legislação e a } \\
\text { SED), para colher dados importantes interdisciplinares (o que é } \\
\text { "tratamento", sua química/física básica, importância social da água } \\
\text { tratada, acesso da sociedade etc.) para depois elaborar texto coletivo. } \\
\text { De tarde, usar tempo para continuar a estudar o que é qualidade da água, } \\
\text { química e social (água para todos, falta de água). } \\
\text { Terminar com texto coletivo sobre "tratamento de água" para consumo } \\
\text { humano. }\end{array}$ & $\begin{array}{l}\text { Valorizar a água em } \\
\text { todos os sentidos, } \\
\text { como vital. }\end{array}$ \\
\hline 4 & $\begin{array}{l}\text { Água que bebemos - } 2 \\
\text { De manhã, estudar o comércio da água; se possível, visitar um } \\
\text { supermercado e observar, anotar como se vende água, qual sua } \\
\text { matemática (preços, por exemplo), qual sua química/física; de onde } \\
\text { vem; questões de acesso social da água; regime de chuvas ou sua falta. } \\
\text { De tarde, com apoio em textos e materiais informativos e analíticos, } \\
\text { estudar o tema: "Valor vital da água", em texto individual. } \\
\text { Para evitar que estudantes terminem rápido e saiam, reservar no fim } \\
\text { uma brecha para exposição sorteada. }\end{array}$ & $\begin{array}{l}\text { Água como bem } \\
\text { comum e como } \\
\text { mercadoria. }\end{array}$ \\
\hline 5 & $\begin{array}{l}\text { Água vai ser o bem mais importante da humanidade, } \\
\text { provavelmente } \\
\text { De manhã: } \\
\text { Posição brasileira no planeta (maior reserva de água doce do mundo); } \\
\text { estatísticas nacionais e internacionais sobre disponibilidade da água } \\
\text { potável; falta de água no Nordeste } \\
\text { De tarde: } \\
\text { Discussão e texto coletivo. Apresentação no fim do dia. }\end{array}$ & Situação do Brasil. \\
\hline
\end{tabular}

SEMANA 3

\begin{tabular}{l|c|r} 
Dia & Tópicos & Objetivo \\
\hline
\end{tabular} 


\begin{tabular}{|c|c|c|}
\hline 1 & $\begin{array}{l}\text { Acertos de conteúdo curricular, déficits, recuperações } \\
\text { Com base nas duas semanas anteriores, diagnosticar a situação da } \\
\text { turma e de cada um, indicando necessidades tópicas de estudo, em } \\
\text { especial em matemática e correlatas. Avaliando as elaborações, } \\
\text { sopesar a capacidade autoral em termos científicos. } \\
\text { Usar o dia para tais acertos, indicando exercícios, práticas e mesmo } \\
\text { aulas, se forem úteis à aprendizagem autoral. } \\
\text { Fazer acompanhamento personalizado, para que cada estudante saiba } \\
\text { como se encontra em termos da expectativa dos professores, } \\
\text { avaliando sua produção, passo a passo. } \\
\text { Oferecer a cada estudante (de maneira individualizada ou grupal) } \\
\text { chance de recuperação. }\end{array}$ & $\begin{array}{l}\text { Garantir a cada qual o } \\
\text { direito de aprender } \\
\text { autoralmente. }\end{array}$ \\
\hline 2 & $\begin{array}{l}\text { Dia para ciências exatas e naturais, sobre o pano de fundo da } \\
\text { água. } \\
\text { Propostas de como estudar/pesquisar/elaborar matemática, física, } \\
\text { química e biologia etc., de modo a satisfazer a carga curricular, } \\
\text { usando problematizações instigantes com água. Apoio docente em } \\
\text { termos de materiais de estudo e pesquisa. } \\
\text { Terminar o dia com texto coletivo sobre "quantidades físicas e } \\
\text { biológicas da água". }\end{array}$ & $\begin{array}{l}\text { Valores quantitativos } \\
\text { da água. }\end{array}$ \\
\hline 3 & $\begin{array}{l}\text { Dia para ciências sociais e humanas, sobre o pano de fundo da } \\
\text { água. } \\
\text { Propostas para estudar/pesquisar/elaborar história/geografia, artes e } \\
\text { literatura, sociologia e filosofia, educação física, com } \\
\text { problematizações instigantes da água. } \\
\text { Terminar o dia com texto individual sobre "qualidade social da } \\
\text { água". }\end{array}$ & $\begin{array}{l}\text { Valores qualitativos da } \\
\text { água. }\end{array}$ \\
\hline 4 & $\begin{array}{l}\text { Água no cotidiano das pessoas e famílias } \\
\text { Água para a elite da sociedade. } \\
\text { Água em fartura. Piscinas, pesca chique, turismo. Chuveiros } \\
\text { perdulários. } \\
\text { Desperdício da água. } \\
\text { Organizar sessão de fotos sobre a temática ou do próprio celular. } \\
\text { Terminar o dia com texto coletivo sobre propostas de uso sustentável } \\
\text { da água. }\end{array}$ & $\begin{array}{l}\text { Uso sustentável da } \\
\text { água. }\end{array}$ \\
\hline 5 & $\begin{array}{l}\text { Água no cotidiano das pessoas e famílias } \\
\text { Água para os marginalizados da sociedade } \\
\text { Água que o pobre bebe } \\
\text { Áreas periféricas sem esgoto e escoamento pluvial - pode-se } \\
\text { imaginar visita programada a certos locais para colher dados. Água } \\
\text { poluída. } \\
\text { Organizar sessão de fotos sobre a temática ou do próprio celular. } \\
\text { Terminar o dia com texto individual sobre água potável como } \\
\text { direito de todos. } \\
\text { Para evitar que estudantes concluam rápido e saiam, programar } \\
\text { apresentações sorteadas. }\end{array}$ & $\begin{array}{l}\text { Analisar } \\
\text { problemas/desafios de } \\
\text { acesso social à água } \\
\text { potável. }\end{array}$ \\
\hline
\end{tabular}

A quarta semana será de "colheita", se tivermos plantado bem. Deverão ocorrer dois textos extensos/intensos, um coletivo, outro individual, nos quais os estudantes possam demonstrar seu aprendizado autoral no tópico água, curricularmente adequado. Ou seja, é preciso garantir que a carga curricular seja respeita, bem como o avanço nas habilidades autorais.

\begin{tabular}{|l|l|l|}
\hline \multicolumn{3}{|c|}{ SEMANA 4 } \\
\hline \hline Dia & Tópicos & Objetivo \\
\hline
\end{tabular}




\begin{tabular}{|c|c|c|}
\hline 1 & $\begin{array}{l}\text { Envolver os estudantes na estruturação de uma carta aos vereadores } \\
\text { ou deputados estaduais, em termos de urgir políticas da água para o } \\
\text { estado e para Campo Grande. Se for para os vereadores, atacar a } \\
\text { questão dos rios/córregos da cidade, suas enchentes, suas poluições. } \\
\text { Se for para os deputados estaduais, pode-se propor políticas da água } \\
\text { para o pantanal. } \\
\text { Cuidar que a proposta tenha sentido curricular, não apenas "político" } \\
\text { - os estudantes precisam saber trabalhar cientificamente o que querem } \\
\text { propor, de maneira interdisciplinar. } \\
\text { Ao fim do dia, elaborar a carta, representando a todos os estudantes. }\end{array}$ & $\begin{array}{l}\text { Exercitar a cidadania } \\
\text { do estudante em } \\
\text { termos } \\
\text { compromisso de } \\
\text { sustentável com água. }\end{array}$ \\
\hline 2 & $\begin{array}{l}\text { Dia de estudo aprofundado sobre as grandes questões da água, no } \\
\text { planeta, no Brasil, no MS, em Campo Grande, do ponto de vista } \\
\text { interdisciplinar, tendo a proposta curricular no fundo. } \\
\text { Estudo em grupo, sobre a mesma temática, ou sobre diversas } \\
\text { temáticas, abrindo espaço também para preferências dos estudantes. } \\
\text { Foco na questão quantitativa da água, propriedade química/física, } \\
\text { biológica. Água potável pode acabar? Teremos guerras por conta da } \\
\text { carência de água? Águas envenenadas, poluídas, acidificadas. } \\
\text { Poluição dos mares. Lugares onde água sumiu. Diminuição do volume } \\
\text { dos rios e da vida no rio. Desertos e desertificação. }\end{array}$ & $\begin{array}{l}\text { Entender água como } \\
\text { bem escasso, em risco. }\end{array}$ \\
\hline 3 & $\begin{array}{l}\text { Dia de estudo aprofundado sobre as grandes questões da água, no } \\
\text { planeta, no Brasil, no MS, em Campo Grande, do ponto de vista } \\
\text { interdisciplinar, tendo a proposta curricular no fundo. } \\
\text { Estudo em grupo, sobre a mesma temática, ou sobre diversas } \\
\text { temáticas, abrindo espaço também para preferências dos estudantes. } \\
\text { Foco na questão social qualitativa da água, acesso à água potável, } \\
\text { regiões secas e seus dilemas, uso predatório dos rios e da água, } \\
\text { sustentabilidade da água. Água no imaginário popular e literário. } \\
\text { Importância dos rios para a vida social e econômica do país e do } \\
\text { estado. }\end{array}$ & $\begin{array}{l}\text { Entender água como } \\
\text { bem social preciso. }\end{array}$ \\
\hline 4 & $\begin{array}{l}\text { Dia de elaboração. } \\
\text { De manhã: coletiva (em grupos) } \\
\text { Tema livre } \\
\text { Vale muito um texto multimodal } \\
\text { De tarde: individual } \\
\text { Tema livre } \\
\text { Vale muito mesclar o texto com imagens, fotos, hiperlinks. }\end{array}$ & $\begin{array}{l}\text { O que se aprendeu } \\
\text { sobre água, com } \\
\text { sentido curricular. }\end{array}$ \\
\hline 5 & $\begin{array}{l}\text { Feira da água } \\
\text { Dia reservado para demonstrar o que se aprendeu sobre água em quatro } \\
\text { semanas consecutivas, com base em pesquisa e elaboração própria. } \\
\text { Pode ser organizada só para a escola, ou para as famílias, bairro, } \\
\text { sociedade, ou para a SED, universidade... } \\
\text { Ficaria bem alguma montagem teatral ou de vídeo para discutir temas } \\
\text { relativos à água. } \\
\text { Ao final, revelar os portfólios, com as produções das quatro semanas. } \\
\text { Alguma comemoração. }\end{array}$ & $\begin{array}{l}\text { Valorizar a ralação de } \\
\text { quatro semanas. }\end{array}$ \\
\hline
\end{tabular}

Esta proposta organizacional é apenas ilustrativa, um exemplo, nada mais. Tem também o tom de primeira experiência de pesquisa longa na escola. Institucionalizando este tipo de aprendizagem autoral, o fluxo pode tomar outros rumos, ser mais flexível, ou não, com maior liberdade dos estudantes ou não. É importante não ficar em extremos, por exemplo: atrelar-se demais ao currículo; ou ignorar. Conteúdo é sempre importante, mas não menos o desenvolvimento das atividades de aprendizagem. Na prática, a proposta acima se dedica a organizar atividades de aprendizagem dos estudantes, sob o olhar orientador e avaliador 
docente. Este processo pode ser extremamente revelador, tanto das virtudes estudantis, quanto de seus vazios, em especial de matemática e correlatos. Ao final das quatro semanas, resta para os professores saber retirar as conclusões adequadas do tirocínio percorrido, para contribuir com acuidade tanto mais meticulosa para o desenvolvimento geral e personalizado dos estudantes.

É possível, por exemplo, que após quatro semanas de pesquisa extensa e intensa, seja o caso "parar para pensar", no sentido de enfrenar déficits mais dramáticos curriculares nos estudantes, organizando sessões de estudo e pesquisa específicas para alunos específicos, também no sábado, se for o caso. Tratamento individualizado pode ser necessário, para garantir o direito de todos de aprender. Exercícios disciplinares também podem ser indicados, quando o déficit for particularmente dramático. Como regra, ninguém pode ficar para trás. Se o estudante não comparece, busca-se em casa. Evitar, de todos os modos, a evasão.

\section{RAZÕES DA APRENDIZAGEM AUTORAL}

Este esboço de proposta atende a uma mudança profunda na vida escolar, deixando de lado o instrucionismo renitente e secular que tem marcado as políticas educacionais, independentemente da ideologia partidária. O acento sai do sistema de ensino e vai para o sistema de aprendizagem, assegurando ao estudante o direito de aprender, não apenas de "ver" conteúdo, sem reconstruí-los. O papel docente não é secundarizado, como se fosse figura dispensável, nem é assim que o centro de tudo é o aluno. Na ideia da "comunidade de aprendizagem" todos têm seu papel fundamental, desde o diretor até a merendeira, incluindo também a família e a comunidade. O que mais vale é a relação pedagógica tecida pela aprendizagem autoral, retirando o estudante da posição de "vítima de aula" (Demo, 2017) e trazendo-o para o protagonismo de seu próprio desenvolvimento, à medida que se torna possível um estilo de aprendizagem "transformadora" (Mezirow \& Associates, 2000. Taylor \& Cranton, 2012), inspirado em Paulo Freire ou em posições avançadas da neurociência e biologia (Hoffman, 2019). O estudante não pode tudo, ou faz o que quiser, ou decide se gosta ou não gosta da escola, mas precisa ter espaço próprio para envolver-se por motivação intrínseca, o que pode incidir fortemente na redução ou mesmo eliminação da indisciplina. Estudantes que aprendem a gostar de estudar gastam seu tempo curtindo sua autoria, naturalmente. Isto pode também evitar a evasão escolar, em geral elevada no ensino médio. 
A mudança maior, porém, está no professorado. Primeiro, o esboço acima indica a trabalheira complexa e exigente de organizar 4 semanas de pesquisa em torno da água, em termos de definir objetivos semanais e diários, compatibilizar as problematizações com a carga curricular, acompanhar de perto o movimento estudantil, em especial sua produção, fazendo diagnósticos diários que facultem assegurar a autoria crescente, anotar os déficits e engendrar recuperações adequadas, trabalhar o estudante de modo personalizado, cuidar do fluxo, aprendendo do erros e acertos, avaliando na celeridade possível para dar imediato feedback e assim por diante. Segundo, em termos práticos, busca-se oferecer ao estudante a chance de se tornar "autor, cientista, pesquisador", conforme sua idade e progressão escolar, nem demais, nem de menos, como pretendia Vygotsky em sua "zona do desenvolvimento proximal". Professores são profissionais da aprendizagem, stricto sensu, exemplos convincentes para os alunos do que é aprender como autor (Demo, 2015), exigindo autorrenovação permanente, produção própria constante, crescimento profissional incansável, muito distante da reprodução copiada para ser copiada de conteúdo curricular. Professores precisam cuidar-se meticulosamente, em termos profissionais, pois o estudantes demandam atualização incessante científica e metodológica, carecendo ser, claramente, "autores, cientistas, pesquisadores". A educação científica que cumpre assegurar aos alunos precisa estar resolvida nos professores. Tomando em conta o estado dramático da matemática, esta precisa ter realce incansável, exigindo dos licenciados da área e ou próximos dela (física, química etc.) empenho muito particular.

Propostas de formação permanente tradicionais já não fazem sentido, porque são parte do sistema de ensino, como "especialização", por exemplo. São cursos instrucionistas que nunca impactam a aprendizagem do estudante, embora possam ser úteis lateralmente aos docentes, em termos de melhoria salarial. Jornadas pedagógicas, facilmente organizadas no espírito do sistema de ensino, também são inócuas: nunca produzem minimamente alguma mudança perceptível nos estudantes; talvez sejam até contraproducentes. Embora sempre se possa contemplar a necessidade de docentes fazerem "cursos", é fundamental não cair na arapuca instrucionista vigente, como são as pós-graduações lato sensu: não produzem aprendizagem. Se for para fazer cursos, é preciso sair, de vez, do espírito dos "cursinhos", tipicamente imbecilizantes, como atestam os resultados do Enem. Cursos precisam ser "híbridos", no sentido de aliar autoria impressa e multimodal, com predominância do tempo virtual, caracterizando-se como experiência inequívoca de aprendizagem autoral. É fundamental que professores tenham este tipo de prática, em cursos híbridos que proponham 
atividades de aprendizagem que podem ser reconstruídas na escola. A rigor, os professores, deformados na faculdade, nunca tiveram esta prática, razão pela qual muitos reagem perplexos contra a expectativa de que se tornem autores, cientistas, pesquisadores, como se fosse coisa do outro mundo. É precisamente deste mundo, do mundo turbinado por ciência e tecnologia. Transmitir conteúdo tornou-se reles instrucionismo impróprio, para não dizer contraproducente, não só porque os conteúdos estão todos disponíveis, em especial na web sob todos as disfarces imagináveis, mas principalmente porque deforma a noção de aprendizagem em favor de vezos instrucionistas completamente ultrapassados. Os dados são veementes em indicar que estamos à deriva, caindo ladeira abaixo, numa escola pretérita.

O esboço acima, a rigor, organiza "atividades de aprendizagem", das quais depende a autoria estudantil. Cuida do conteúdo, mas não menos das habilidades básicas da autoria, das quais o estudante precisa para manter-se autorrenovado a vida toda. Sua produção própria é a graça da escola. Por ela é também avaliado, não para ser classificado ou rotulado, talvez humilhado, mas para garantir seu direito de aprender. Lidar com ciência é imprescindível na quadra atual, incluindo nisto também perícias digitais urgentes, não, porém, para reproduzir/plagiar o currículo, mas para reinventá-lo por completo. O mínimo que se espera da escola é que cuide da formação exigida pelos tempos atuais, não por tempos já pretéritos, tornando-se, então, imprescindível que os professores possam dar conta desse desafio. A mudança para o sistema de aprendizagem é obra docente, fundamentalmente, mesmo que tenha sido despreparado como mero profissional do ensino. O possível efeito emancipatório da aprendizagem fica por conta da qualidade docente, como instrumentação, e da qualidade discente, como objetivo em si.

No início, a mudança pode parecer difícil, atrapalhada, obscura, mas, com o tempo, torna-se o óbvio ululante, quando vemos que estudantes podem realmente gostar de estudar, descobrindo a gana de desenvolver sua autoria. A partir daí, as coisas andam mais ou menos por si, sendo viável alargar crescentemente as margens de liberdade dos estudantes, permanecendo os docentes em sua posição de orientadores e avaliadores, solicitamente presentes. É sempre o caso cuidar que estudantes particularmente motivados não só façam o tema de suas vidas, mas lidem com todos os conteúdos, mesmo que sempre seja o caso descobrir vocações específicas acadêmicas (matemática, por exemplo). Toda escola deveria ter sua marca acadêmica destacada, também para corresponder a propensões dos estudantes, quando escolhem onde se matricular. É pertinente que uma escola, para dar um exemplo, se incline para matemática e programação digital, caprichando tanto mais nessas áreas, sem descurar das outras. Ao final, não valem formatos rígidos organizacionais, porque 
aprendizagem é uma aventura aberta, não um pacote fechado. No esboço acima, podemos ver o quanto pode variar, sendo mais flexível ou não, montando fluxos diferenciados nas semanas, mudando objetivos mais e menos imediatos, dependendo também da temática. Problematizações interdisciplinares são cruciais, porque agregam o desafio de encarar questões às quais podemos aplicar soluções engendradas autoralmente. Assim, a escola vai tomando o ar de laboratório científico, onde os estudantes, cuidando de sua formação intelectual e cívica, aprendem a lidar com instrumentações poderosas de como intervir na realidade, conduzir seu destino, tornar-se prócer da sociedade.

A proposta é interdisciplinar tipicamente, mesclando todos os conteúdos curriculares numa empreitada coletiva, exigindo, então, planejamento coletivo, um dos maiores desafios para os professores. No entanto, podemos aceitar propostas disciplinares, seja como fase inicial em preparação da interdisciplinaridade sequente, ou como lance eventual, quando algum professor ou grupo menor de professores decide organizar a produção discente em termos de aprendizagem autoral. Fiz isso em texto recente (Demo, 2018a), no qual montei a sociologia em torno de 20 temas ou problematizações que pedem pesquisa e elaboração própria. Naturalmente, este procedimento exige a desconstrução dos 50 minutos e dispensa aula, já que, tomando a sério a atividade de estudo, pesquisa, elaboração, o tempo não pode ser exprimido em lapsos caricatos. Numa escola de Campo Grande, tive a oportunidade de assistir a uma exposição de um grupo de alunos do $2^{\circ}$ ano do ensino médio sobre a série de Finobacci, que define padrões recorrentes físicos e biológicos, tendo os estudantes, sob motivação do professor de matemática, conduzido uma pesquisa muito convincente e avançada, apenas em matemática. Alguns anos antes, o mesmo professor havia motivado um grupo de meninas a fazerem um vídeo de celular para demonstrar o teorema de Pitágoras, também com êxito notável. Como o planejamento coletivo é desafio contundente, entende-se que pode ser adequado passar algum tempo (um semestre, digamos) ensaiando aportes disciplinares que já inauguram a noção de aprendizagem autoral com base na pesquisa. $\mathrm{Na}$ base de tais experiências está sempre a noção de "atividades de aprendizagem", no contexto do sistema de aprendizagem, não de ensino. É sempre preferível, porém, o ambiente interdisciplinar.

Ainda, considera-se mais importante, pedagogicamente falando, o trabalho em equipe, apesar dos riscos. Entre os riscos mais iminentes está o "aproveitador" que se esconde atrás do trabalho do grupo: enquanto a turma rala, ele apenas assina o texto. Para evitar este risco, convém que, antes de se chegar ao texto coletivo, se exijam textos individuais 
elaborados, também porque isto enriquece sobremaneira a discussão. É importante estabelecer como regra de trabalho o aporte fundamentado, argumentado, elaborado, não o chute alegre, ou permanecer calado, ou sumir. Aprender é uma atividade social eminentemente, embora também detenha o lado individual, que não pode ser esquecido. No ambiente de grupo, a diversidade pode ser um trunfo, não um defeito, sem falar que um pode contribuir com o outro.

\section{CONCLUSÃO}

Pode parecer trivial insistir em "atividades de aprendizagem" e até mesmo levar um susto, quando se alega que elas não existem nas escolas. Tornou-se tão comum fazer a escola girar em torno de aula, prova e repasse, que não se imagina outra coisa. Aí está o ponto: a escola considera aprendizagem algo estranho na escola. Vemos isso escancaradamente na matemática: quando apenas $4.6 \%$ dos estudantes do ensino médio aprenderam matemática em 2017 (em 2015, a cifra foi de 7.3\%, em queda, por conseguinte) a escola está, literalmente, no mundo da lua, totalmente alienada. Não falta aula. Ao contrário, em geral sobra. Falta aprendizagem, da maneira mais lancinante imaginável. O estudante passa seu tempo - na verdade, o perde - lidando com conteúdo que precisa regurgitar na prova, não levando nada para vida. Terminar o ensino médio sem ter aprendido quase nada de matemática, é entrar na vida sem lenço e documento! O INAF (Indicador de Alfabetismo Funcional) do Instituto Paulo Montenegro constatou, para 2018, que apenas 12\% dos adultos brasileiros são "proficientes" (traduzo como "sabem pensar") (Ação Educativa/Instituto Paulo Montenegro. 2018): é o que sobrou, miseravelmente, de 12 anos de estudo, um tempo quase todo perdido.

Por essas e outras, concluo que o atual sistema de ensino é um suicídio nacional, questão extremamente mais grave do que "ideologia", "escola sem partido", excessos relativos a posições das esquerdas (em geral personificadas em Paulo Freire) doutrinadoras, mas que teimamos em não diagnosticar serenamente. Para que aprendizagem exista e seja a razão de ser da escola, não mero ensino da aula copiada para ser copiada, urge reinventar o professor: ele é problema, certamente, porque está no mesmo barco instrucionista, mas é principalmente a solução. Estudante aprende bem com professor que aprende bem.

\section{REFERENCIAS}

Revista Educação e Ciências Sociais, Salvador, v.4, n.6, 2021. 
AÇÃO EDUCATIVA/INSTITUTO PAULO MONTENEGRO. 2018. Inaf Brasil 2018. Resultados preliminares. Pesquisa gera conhecimento; o conhecimento transforma. São Paulo - http://acaoeducativa.org.br/wp-ontent/uploads/2018/08/Inaf2018_Relat\%C3\%B3rioResultados-Preliminares_v08Ago2018.pdf .

BID - ELACQUA, G., HINCAPIÉ, D., VEGAS E., ALFONSO, M. 2018. Profissão Professor na América Latina - Por que a docência perdeu prestígio e como recuperá-lo? BID, N.Y. https://publications.iadb.org/handle/11319/8953.

BOK, D. 2017. The struggle to reform our colleges. Princeton U. Press. BOYKIN, A.W. \& NOGUERA, P. 2011. Creating the Opportunity to Learn: Moving from research to practice to close achievement gap. ASCD, Washington.

BRUYCKERE, P., KIRSCHNER, P.A., HULSHOF, C.D. 2015. Urban myths about learning and education. Academic Press, London.

CHAPLIN, C. 2019. Tempos Modernos-https://www.youtube.com/watch?v=XFXg7nEa7vQ

COOPER, R. \& MURPHY, E. 2016. Hacking project based learning: 10 easy steps to PBL and Inquiry in the classroom. Times 10 Publications, N.Y.

DAVIDSON, C.N. 2017. The new education: How to revolutionize the University to prepare students for a world in flux. Basic Books, N.Y.

DEMO, P. 2015. Aprender como Autor. Gen, São Paulo.

DEMO, P. 2017. Vítima de Aula - Algumas razões por que não se aprende na escola brasileira. SED, Gov. MS, Campo Grande - https://docs.google.com/document/d/e/2PACX1vQH7iANCrxZj3SdPTuIdqYuibz9beh_eKfiDtY66h3pg0r919ps9ziivJhZpqkN4BAvgHpU6 $\underline{\mathrm{EkAbEcv} / \mathrm{pub}}$

DEMO, P. 2017a. Questionando a Graduação - https://docs.google.com/document/d/1yOhRkIY-Lb_Y2P-0eVntZZQBY79MbPY4fSdA8TSol4/pub

DEMO, P. 2018. Atividades de Aprendizagem - Sair da mania do ensino para comprometerse com a aprendizagem do estudante. SED, Gov. MS, Campo Grande https://drive.google.com/file/d/1FKskDCxNB422PVhrjrDjD48S4cjsb77-/view

DEMO, P. 2018a. Sociologia Pequena - Crítica autocrítica social ao alcance. Alphabeto, Ribeirão Preto.

DINTERSMITH, T. 2018. What school could be: Insights and inspiration from teachers across America. Princeton U. Press, Princeton.

EYLER, J.R. 2018. How humans learn: The science and stories behind effective college teaching. West Virginia U. Press. 
FREIRE, P. 1989. A Importância do ato de ler. Cortez, São Paulo http://educacaointegral.org.br/wp-content/uploads/2014/10/importancia_ato_ler.pdf HOFFMAN, D. 2019. Vemos a realidade como ela é? https://www.ted.com/talks/donald_hoffman_do_we_see_reality_as_it_is?language=pt-br

KAPA, R. 2019. Enem 2018: Confira as notas máximas e mínimas em cada uma das provas. O Globo - Enem e vestibular - https://oglobo.globo.com/sociedade/educacao/enem-evestibular/enem-2018-confira-as-notas-maximas-minimas-em-cada-uma-das-provas$\underline{23381845}$

KNUDSEN, J., STEVENS, H., LARA-MELOY, T., KIM, H-J., SCHECHTMAN, N. 2017. Mathematical argumentation in middle-school - The what, why, and how: A step-by-step guide with activities, games, and lesson planning tools. Corwin, Thousand Oaks.

LANG, J.M. 2013. Cheating Lessons. Harvard U. Press, Cambridge.

LARMER, J., MERGENDOLLER, J., BOSS, S. 2015. Setting the Standard for Project Based Learning. ASCD, Washington.

LINN, M.C. \& EYLON. B.-S. 2011. Science Learning and Instruction - Taking advantage of technology to promote knowledge integration. Routledge, N.Y.

MANOVICH, L. 2013. Software takes command. Bloomsbury, N.Y.

MEANS, A.J. 2018. Learning to save the future: Rethinkinhg education and work in an era of digital capitalism. Routledge, London.

MEZIROW, J. \& ASSOCIATES. 2000. Learning as Transformation - Critical perspectives on a theory in progress. Jossey-Bass, San Francisco.

OECD. 2015. Students, computers, and Learning -

https://www.mecd.gob.es/dctm/inee/internacional/pisa-2012-studentscomputers.pdf?documentId=0901e $72 \mathrm{~b} 81 \mathrm{e} 9 \mathrm{cc} 75$

PACHECO, J. 2014. Aprender em Comunidade. SM, São Paulo.

PACHECO, J. 2017. Reconfigurando a escola - Transformar a educação. Cortez, São Paulo.

PAHOMOV, L. 2014. Authentic Learning in the digital age: Engaging students through inquiry. ASCD, Washington.

POSECZNICK, A. 2017. Selling hope and college: Merit, markets, and recuritment in an unranked school. IRL Press. N.Y.

RUSHKOFF, D. 2010. Program or be programmed. OR Books, N.Y.

SAEB. 2018. Saeb 2017 revela que apenas 1.6\% dos estudantes brasileiros do ensino médio demonstraram níveis de aprendizagem considerados adequados em língua portuguesa. Inep/MEC, Brasília - http://portal.inep.gov.br/artigo/lasset_publisher/B4AQV9zFY7Bv/content/saeb-2017-revela-que-apenas-1-6-dos- 
estudantes-brasileiros-do-ensino-medio-demonstraram-niveis-de-aprendizagemconsiderados-adequados-em-lingua-portug/21206

SLOTTA, J.D. \& LINN, M.C. 2009. Wise Science - Web-based inquiry in the classroom. Teachers College Press, N.Y.

TAYLOR, E.W., CRANTON, P. \& Associates. 2012. The Handbook of Transformative Learning - Theory, research, and practice. Jossey-Bass, San Francisco.

VYGOTSKY, L.S. 1989. A Formação Social da Mente. Martins Fontes, São Paulo.

VYGOTSKY, L.S. 1989a. Pensamento e Linguagem. Martins Fontes, São Paulo.

WORLD BANK (WB). 2018. Learning - To realize education's promise. The Wolrd Bank, Washington. https://openknowledge.worldbank.org/handle/10986/28340 